\title{
DEVISING A NEW TECHNIQUE TO REDUCE HIGHWAY BARRIER
}

\section{ACCIDENTS}

\author{
G.Udayakumar ${ }^{1}$, S.Chandralekha ${ }^{2}$ \\ ${ }^{1} P G$ Scholar, M.E., Industrial Safety Engineering, K.S.Rangasamy College of Technology, Tamilnadu, India \\ ${ }^{2}$ Assistant Professor, Dept. of Mechatronics Engineering, K.S.Rangasamy College of Technology, Tamilnadu, India
}

\begin{abstract}
In transportation sector, the roadway transportation rank high in travel and also in reportable accidents. Nowadays, there are various changes in road network and infrastructure developments done in our country. But according to the statistical report "Road Accident in India 2012" released by the Government of India, Ministry of Road Transport and Highways (MORTH) the reportable accidents, injury and fatality rates were in increasing order for the past decade up to 2011 and there is only a slight decline in the year 2012. When compared with other States and Union Territories, Tamilnadu tops two in road accidents and fatalities. In these accidents a considerable amount of accidents are due to vehicle-divider and vehicle-barrier collisions. This paper suggests and devises flexible median divider using suitable polymer material, so as to reduce the risk level during median divider accidents.
\end{abstract}

Keywords: Flexible Barrier, Impact attenuator, Median divider accident, Risk reduction $* * *$

\section{INTRODUCTION}

Road accidents are a human tragedy, which involve high human suffering. They impose a huge socio-economic cost in terms of untimely deaths, injuries and loss of potential income. The ramifications of road accidents can be colossal and its negative impact is felt not only on individuals, their health and welfare, but also on the economy. Consequently, road safety has become an issue of national concern.

\subsection{Road Accident in India}

In India, the expansion in the road network, surge in motorization and a rising population of a country contribute towards increasing numbers of road accidents, road accident injuries and road accident fatalities. Between 1970 and 2012 , the number of road accidents increased by 4.3 times accompanied with 9.5 times increase in road accidents fatalities and 7.3 times increase in the number of persons injured in road accidents in India.

The Compound Annual Growth Rate (CAGR) of number of road accidents and persons injured in road accidents in the country during the decade 2002 to 2012 has decreased at 1.9 percent and 2.2 percent respectively as compared to earlier decade i.e. 1992 to 2002, when the same was reported at 4.0 percent and 4.3 percent respectively. However, in case of road accident fatalities, the CAGR at 5.0 percent showing increase during the decade (2002 to 2012) over the decade (1992 to 2002), when the same was at 0.6 percent.

\subsection{Road Traffic Collisions}

Road traffic collisions generally fall into one of four common types:

- Lane departure crashes, which occur when a driver leaves the lane they are in and collide with another vehicle or a roadside object. These include head on collisions and run-off-road collisions.

- Collisions at junctions include rear-end collision and angle or side impacts.

- Collisions involving pedestrians and cyclists

- Collisions with animals

Although other types of collision do occur. Rollovers are not very common, but lead to greater rates of severe injury and death. Some of these are secondary events that occur after a collision with a run-off-road crash or a collision with another vehicle.

\subsection{Causes of Road Accidents}

The high socio-economic cost of the injuries and fatalities, occurring due to road accidents, and the need for effective policies for curbing road accidents make it imperative to study the causes of road accidents. The various major causes of Road Accidents are listed below.

- Fault of Driver

- Fault of Cyclist

- Fault of Pedestrian

- Defect in Condition of Motor Vehicle

- Defect in Road Condition

- Weather Condition

- Fault of Driver of other vehicle

- Fault of Passenger

- Poor Light Condition

- Other Causes

\subsection{Traffic Barriers}

Traffic barriers, sometimes called crash barriers keeps the vehicles within their roadway and prevent vehicles from colliding with dangerous obstacles such as boulders, 
buildings, walls or large storm drains. Traffic barriers are also installed at the road side to prevent errant vehicles from traversing steep (non-recoverable) slopes or entering deep water. Traffic barriers are installed within medians of divided highways to prevent errant vehicles from entering the opposing carriageway of traffic and help to reduce headon collisions. Some of these barriers, designed to be struck from either side, are called median barriers. Crash barriers can also be used to protect vulnerable areas like school yards, pedestrian zones or fuel tanks from errant vehicles. The barriers are designed to minimize injury to vehicle driver and the persons occupying the vehicle, injuries do occur in collisions with traffic barriers.

The traffic barriers categorized by function they serve are

- Roadside barrier

- Median barrier

- Bridge barrier

- Work zone barrier

The traffic barriers categorized by how much they deflect when a vehicle crash into them are

- Flexible barrier

- Semi-Rigid barrier

- Rigid barrier

\subsection{E's of Road Safety}

The Government has adopted a multi pronged strategy to address the issue of road safety based on 4 E's of Road Safety viz.

1. Education

2. Enforcement

3. Engineering

4. Environment and Emergency care.

The scope of the project is to reduce the road accidents and it's severity of the accidents happened by the collision between vehicle and barrier/divider by applying the 4 E's concept of Road Safety and particularly applying Engineering concept.

\subsubsection{Traffic Calming}

Traffic Calming is a set of engineering measures to reduce speeds and volumes of motor vehicle traffic in local areas. The technique has been successfully used in developed countries and hold promise for the developing countries also. Some of the measures include:

- Speed breakers or humps

- Rumble strips

- Crash cushions

- Road narrowing

- Separate cycle tracks

\subsubsection{Traffic Impact Attenuators}

On modern highways like the Expressways and busy National Highways where vehicles travel at high speeds, collision of speeding vehicles with fixed objects (like bridge abutments and structural columns etc.) is a common type of road accidents. The exit gore area in interchanges (i.e., the area downstream from the shoulder intersection point of the main carriageway and an exit road) is common area where serious accidents are known to take place. Traffic Impact Attenuators or Crash Cushions are protective systems which prevent errant vehicles from impacting hazard by either smoothly decelerating the vehicle to a stop when hit headon, or by redirecting it away from the hazard for glancing impacts. These barriers are used to shield rigid objects or hazardous conditions that cannot be removed, relocated or made break way. The main design considerations for attenuators as per Unified Traffic and Transportation Infrastructure Planning \& Engineering Centre (UTTIPEC) released by Delhi Development Authority are

- For Normal containment zone the attenuators should be designed to provide the $15 \mathrm{KN}$ vehicle at $110 \mathrm{~km} / \mathrm{hr}$ and 20 degree angle of impact

- For Low containment zone the attenuators should be designed to provide the $15 \mathrm{KN}$ vehicle at 80 $\mathrm{km} / \mathrm{hr}$ and 20 degree angle of impact

- For High containment zone the attenuators should be designed to provide the $30 \mathrm{KN}$ vehicle at 60 $\mathrm{km} / \mathrm{hr}$ and 20 degree angle of impact

There are many types of traffic impact attenuators in use in developed countries but the ones most relevant to Indian Conditions are:

1. Empty Steel Drum Assembly

2. Hi-Dro Cell cluster and

3. Cushions of scrap tyres

\subsection{ANSYS Software}

ANSYS is an engineering simulation software (ComputerAided Engineering or CAE). It offers engineering simulation sets in engineering simulation that a design process requires. Companies in a wide variety of industries use ANSYS software. The tools put a virtual product through a rigorous testing procedure (such as crashing a car into a brick wall, or running for several years on tarmac road) before it becomes a physical object.

\section{MATERIALS AND METHODS}

The below methodology chart shows that the step by step procedure followed in this project.

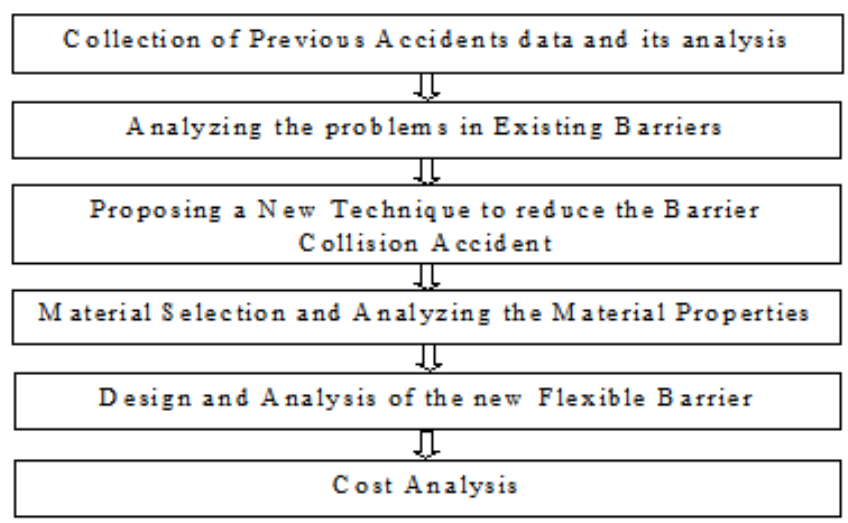

Fig -2.1.: Methodology Chart 
The above chart involves the collection of previous accident data, analysis of problems in existing barriers, analysis of selected material properties, design and analysis of the new flexible barrier using ANSYS software, proposing a new technique to reduce barrier collision accident and cost analysis of the new barrier.

\subsection{Questionnaires Prepared to Collect Road}

\section{Accidents in Thokkavadi}

Questionnaires prepared to collect accident data in the Thokkavadi location.

1. How many road accidents were happened at/near Thokkavadi bus stop from the year 2011 to 2013 ?

2. How many numbers of persons were injured/killed/died due to the accidents happened at/near Thokkavadi bus stop from the year 2011 to 2013 ?

3. How many road accidents were happened at/near Thokkavadi bus stop classified according to type of vehicle from the year 2011 to 2013? e.g.:(Auto/Bus/Two wheeler /Car/Tanker/Lorry/ Trucks/Volvo bus multi axle, etc.,)

4. How many road accidents were happened at/near Thokkavadi bus stop classified according to cause of accident from the year 2011 to 2013 ? e.g. :( Fault of driver/fault of cyclist/fault of pedestrian/defect in condition of motor vehicle/defect in road condition/weather condition/other)

5. How many road accidents were happened at/near Thokkavadi bus stop due to by hitting/near the median divider and barriers from the year 2011 to 2013 ?

6. How many numbers of persons were killed/injured/died due to accidents happened at/near Thokkavadi bus stop due to by hitting/near the median divider and barriers from the year 2011 to 2013 ?

7. How many road accidents happened at/near Thokkavadi bus stop due to the intake of Alcohol/Drugs by the driver from the year 2011 to 2013?

8. How many road accidents were happened at/near Thokkavadi bus stop due to the intake of Alcohol/Drugs by the driver and hitting/near the median divider and barriers from the year 2011 to 2013 ?

9. How many persons were killed/injured/died during the accidents happened at/near Thokkavadi bus stop due to the intake of Alcohol/Drugs by the driver and hitting/near the median divider and barriers from the year 2011 to 2013 ?

10. How many road accidents happened at/near Thokkavadi bus stop due to the exceeding lawful speed by the driver from the year 2011 to 2013 ?

11. How many road accidents were happened at/near Thokkavadi bus stop due to the exceeding lawful speed by the driver and hitting/near the median divider and barriers from the year 2011 to 2013 ?
12. How many persons were killed/injured/died during the accidents happened at/near Thokkavadi bus stop due to the exceeding lawful speed by the driver and hitting/near the median divider and barriers from the year 2011 to 2013 ?

13. How many numbers of accidents occurred at/near Thokkavadi bus stop particularly by hitting/near the median divider and barriers from the year 2011 to 2013 classified according to educational qualification of the driver?

14. How many numbers of accidents occurred at/near Thokkavadi bus stop particularly by hitting/near the median divider and barriers from the year 2011 to 2013 classified according to age of the driver?

15. How many numbers of accidents occurred at/near Thokkavadi bus stop particularly by hitting/near the median divider and barriers from the year 2011 to 2013 classified according to time of occurrence?

16. What is severity rate of the accidents occurred at/near Thokkavadi bus stop particularly by hitting/near the median divider and barriers from the year 2011 to 2013 ?

17. How many pedestrians were killed/injured/died during the accidents happened at/near Thokkavadi bus stop by hitting/near the median divider and barriers from the year 2011 to 2013?

18. Mention any worst case accident happened at/near Thokkavadi bus stop by hitting/near the median divider and barriers from the year 2011 to 2013.

19. How many road accidents happened at/near Thokkavadi bus stop due to not wearing helmet by the driver from the year 2011 to 2013 ?

20. How many road accidents were happened at/near Thokkavadi bus stop due to not wearing helmet by the driver and hitting/near the median divider and barriers from the year 2011 to 2013 ?

\subsection{Accident Data for the Accident Happened}

\section{at/near Thokkavadi Bus Stop}

The accident data of Thokkavadi Bus stop collected from the FIR index of Tiruchengode Rural Police Station from 2011 to 2013 are given in below. The accident data are collected to know the frequency and severity of accidents, type of vehicles involved, time of occurrence in the accident etc...

Table -2.1: Number of road accidents and Barrier accidents: 2011-2013

\begin{tabular}{|c|c|c|c|c|c|c|c|}
\hline \multirow[b]{2}{*}{ YEAR } & \multicolumn{5}{|c|}{ TOTAL ACCIDENTS } & \multicolumn{2}{|c|}{ BARRIER ACCIDENTS } \\
\hline & $\begin{array}{l}\text { Accidents } \\
\text { Recorded }\end{array}$ & $\begin{array}{c}\text { Fatal } \\
\text { Accidents }\end{array}$ & $\begin{array}{c}\text { Number of } \\
\text { persons } \\
\text { Killed }\end{array}$ & $\begin{array}{c}\text { Number of } \\
\text { persons } \\
\text { Injured }\end{array}$ & $\begin{array}{l}\text { Accident } \\
\text { Severity }\end{array}$ & $\begin{array}{l}\text { Number of } \\
\text { Accidents }\end{array}$ & \begin{tabular}{|l|}
$\begin{array}{l}\text { Number } \\
\text { of persons } \\
\text { Injured }\end{array}$ \\
\end{tabular} \\
\hline 2011 & 3 & 1 & 1 & 4 & 33.3 & 0 & $\frac{1 \text { injurea }}{0}$ \\
\hline 2012 & 8 & 1 & 1 & 7 & 12.5 & 1 & 1 \\
\hline 2013 & 3 & 1 & 1 & 2 & 33.3 & 1 & 1 \\
\hline Total & 14 & 3 & 3 & 13 & 21.4 & 2 & 2 \\
\hline
\end{tabular}

The total accidents and barrier collision accidents recorded in the Thiruchengode Rural Police Station is given in the Table 2.1. During 2011 to 2013, a total of 14 road accidents 
were reported in Tiruchengode Rural Police Station of Thokkavadi location. Of these, about 14.3 per cent were barrier collision accidents. During 2011, number of barrier collision accidents is none. During 2012 and 2013, each year is 1 number of barrier collision accidents.

Table -2.2: Share of different vehicles primarily responsible in road accidents: 2011-2013

\begin{tabular}{|c|c|c|c|c|c|c|}
\hline \multirow{2}{*}{ YEAR } & \multicolumn{7}{|c|}{ NUMBER OF ACCIDENTS } \\
\cline { 2 - 7 } & Total & $\begin{array}{c}\text { Two- } \\
\text { Wheelers }\end{array}$ & $\begin{array}{c}\text { Auto- } \\
\text { rickshaws }\end{array}$ & $\begin{array}{c}\text { Car, Jeeps } \\
\text { \& Taxis }\end{array}$ & Buses & $\begin{array}{c}\text { Trucks, Tempos, } \\
\text { Tractors and other } \\
\text { vehicles }\end{array}$ \\
\hline 2011 & 3 & 2 & 0 & 0 & 1 & 0 \\
\hline 2012 & 8 & 3 & 0 & 2 & 1 & 2 \\
\hline 2013 & 3 & 0 & 0 & 2 & 1 & 0 \\
\hline Total & $\mathbf{1 4}$ & $\mathbf{5}$ & $\mathbf{0}$ & $\mathbf{4}$ & $\mathbf{3}$ & $\mathbf{2}$ \\
\hline
\end{tabular}

The types of vehicles involved in the accident are given in Table 2.2 and the Road Accidents as per the time of occurrence is given in Table 2.3.

Table -2.3: Road accidents as per the time of occurrence: 2011-2013

\begin{tabular}{|c|c|c|c|c|c|c|}
\hline \multirow{2}{*}{ TIME } & \multicolumn{3}{|c|}{ NO. OF ACCIDENTS } & \multicolumn{3}{c|}{ PERCENT SHARE IN TOTAL } \\
\cline { 2 - 7 } & $\mathbf{2 0 1 1}$ & $\mathbf{2 0 1 2}$ & $\mathbf{2 0 1 3}$ & $\mathbf{2 0 1 1}$ & $\mathbf{2 0 1 2}$ & $\mathbf{2 0 1 3}$ \\
\hline $06: 00-09.00 \mathrm{hrs}$ (Day) & 0 & 0 & 0 & 0.0 & 0.0 & 0.0 \\
\hline $09: 00-12.00 \mathrm{hrs}$ (Day) & 0 & 0 & 0 & 0.0 & 0.0 & 0.0 \\
\hline $12: 00-15.00 \mathrm{hrs}$ (Day) & 0 & 0 & 1 & 0.0 & 0.0 & $\mathbf{3 3 . 3}$ \\
\hline $15: 00-18.00 \mathrm{hrs}$ (Day) & 1 & 1 & 2 & $\mathbf{3 3 . 3}$ & $\mathbf{1 2 . 5}$ & $\mathbf{6 6 . 7}$ \\
\hline 18:00-21.00 hrs (Night) & 0 & 4 & 0 & 0.0 & $\mathbf{5 0}$ & 0.0 \\
\hline 21:00-00.00 hrs (Night) & 2 & 1 & 0 & $\mathbf{6 6 . 7}$ & $\mathbf{1 2 . 5}$ & 0.0 \\
\hline 00:00-03.00 hrs (Night) & 0 & 1 & 0 & 0.0 & $\mathbf{1 2 . 5}$ & 0.0 \\
\hline 03:00 - 06.00 hrs (Night) & 0 & 1 & 0 & 0.0 & $\mathbf{1 2 . 5}$ & 0.0 \\
\hline Total 24 hrs & 3 & 8 & 3 & $\mathbf{1 0 0 . 0}$ & $\mathbf{1 0 0 . 0}$ & $\mathbf{1 0 0 . 0}$ \\
\hline
\end{tabular}

The above accident reports shows that the barrier collision accident rate is increased more than double times and these accidents mostly happened at night time.

\subsection{Details of some of the Worst Case Barrier}

\section{Collision Accident happened in Various Locations}

The various worst case barrier collision accidents happened in various locations are causing more property damages and losses are given below. The details of worst case accident are collected to found the causes and effect of accident and to give proper solution.

\subsubsection{Accident Data of Kumaragripettai By-pass}

\section{Accident}

An accident happened on 25.10.2013 at 12.00 hrs near Kumaragripettai By-pass (Salem). In this accident lorry driver (aged 30) drives the vehicle loaded with LPG cylinders at over speed, loss his control and hit Eicher vehicle, EB Transformer and 8 Lamp posts. This accident caused property damage worth Rs.8.0 Lakhs to the Tamilnadu Electricity Board. The investigation report says that the fault of driver is the cause of this accident.

\subsubsection{Accident Data of Ammapet-Military Road}

\section{Accident}

This accident is happened on 09.04.2014 at 4.00hrs near Ammapet (Military Road), Salem. In this accident to avoid accident on pedestrian, the private bus driver (aged 32) rammed against the median barrier. Then the front wheels of the bus detached and the diesel tank of the bus hit the median and got fire. About $90 \%$ of bus destroyed in the fire, 3 passengers were suffered burns during accident and about 52 passengers were escaped from fire. The newspaper report says that the fault of driver is the cause of this accident.

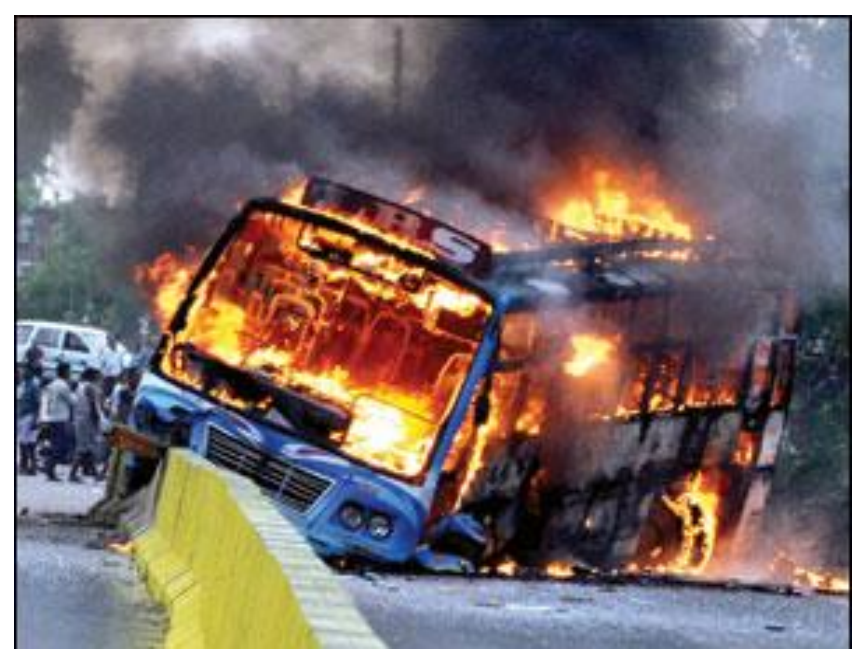

Fig -2.2: Barrier Collision Accident happened at Ammapet, Salem

\subsubsection{Accident data of Harur-GH Road accident}

This accident is happened on 05.12.2013 near Harur Govt. Hospital. In this accident the ambulance driver (aged 34) drives vehicle and rammed against the median barrier placed in front of the Harur, Govt. Hospital.

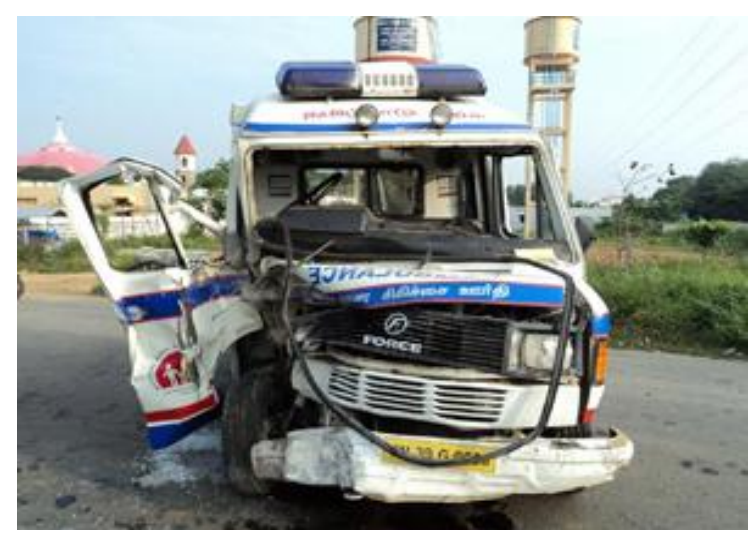

Fig -2.3: Barrier Collision Accident happened near Govt. Hospital, Harur

The news paper report says that, during this accident the person accompanied with the patient got died and patient got injured during accident. 


\subsection{Disadvantages in Existing Barriers}

The RCC Jersey barriers and Flexible PU barriers are mostly used in the medians of road to reduce the accident. But there are some problems in these types of barriers. The various problems found in the existing type of Barriers are shown in below Fig -2.4 and Fig 2.5.

The various disadvantages found in the RCC barrier and PU barrier are given below

- RCC barrier get damaged during collision with vehicles

- And also RCC barrier damage the vehicle which hit on the barrier

- We cannot re-use the damaged RCC barriers

- Flexible PU Barriers get damaged during collision with vehicles

- The PU Barriers cannot withstands the vehicle load during collision

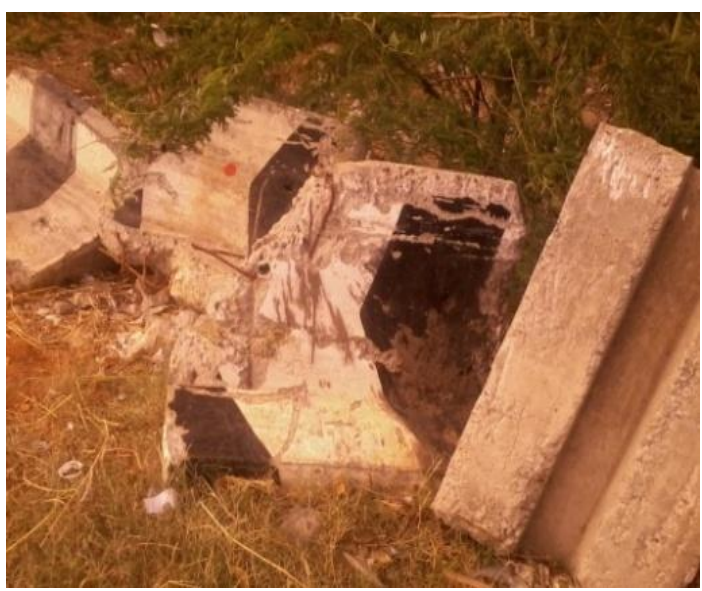

Fig -2.4: RCC Jersey Barriers

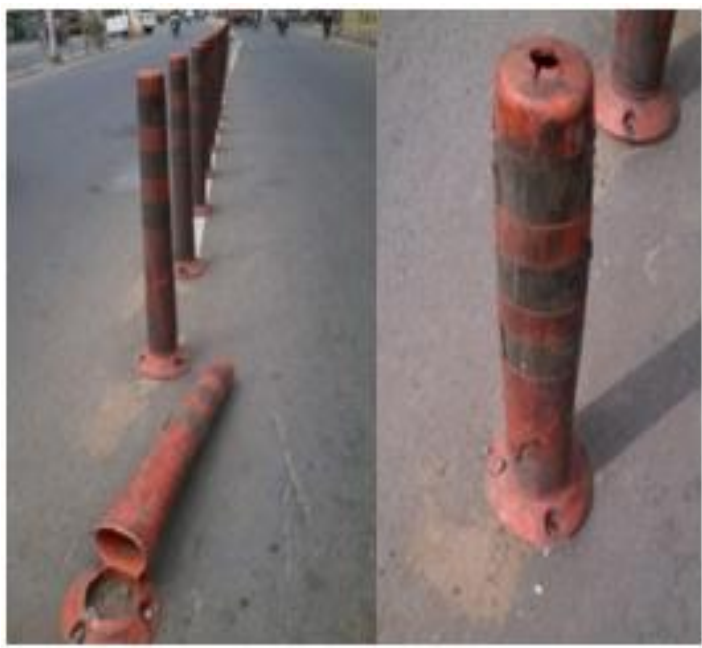

Fig -2.5.: Flexible PU Barriers

The existing types of barriers analyzed to identify the problems disadvantages of the barrier and to give a solution to overcome these problems.

\section{RESULTS AND DISCUSSIONS}

\subsection{Analysis Report of the Collected Accident Details}

During 2011 to 2013, a total of 14 road accidents were reported in Tiruchengode Rural Police Station of Thokkavadi location. Of these, about 14.3 per cent were barrier collision accidents. During 2011, number of barrier collision accidents is none. During 2012 and 2013, each year is 1 number of barrier collision accidents.

The severity of road accidents, measured in terms of persons killed per 100 accidents, is shown the below Chart- 3.1.

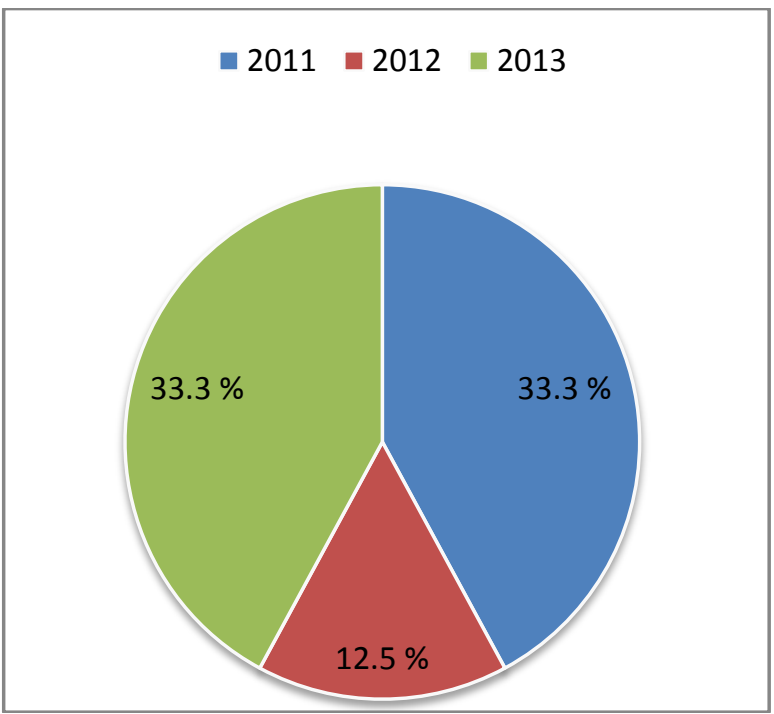

Chart -3.1: Total Accident Severity: 2011-2013

The share of various categories of vehicle in total number of Road Accidents from 2011 to 2013 is given in Chart- 3.2.

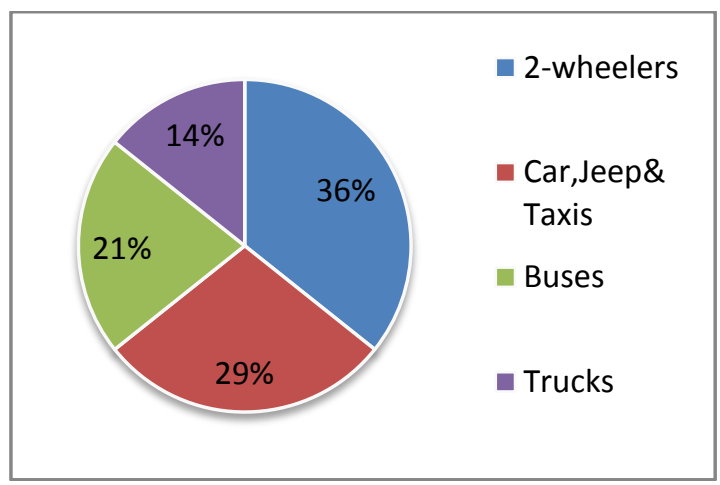

Chart -3.2: Share of various categories of vehicle in total accidents 2012-2013

The share of various distribution of total number of Road Accidents as per time of occurrence from 2011 to 2013 is given in Chart- 3.3. 


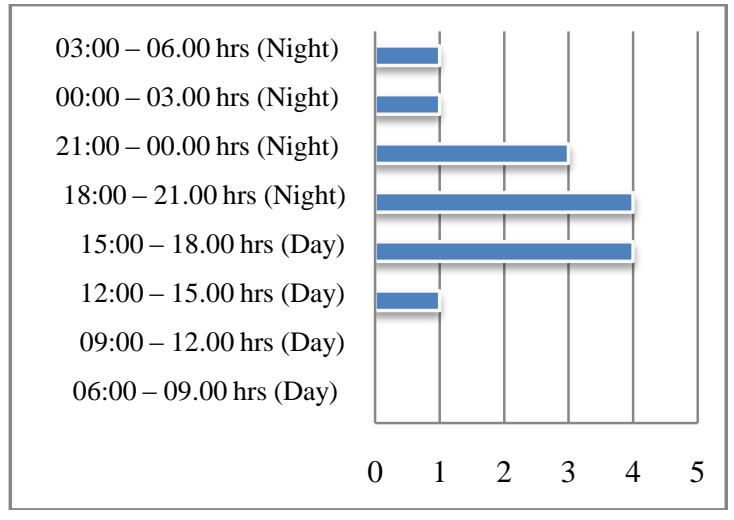

Chart -3.3: Distribution of Total Number of Road Accidents as per time of occurrence: 2011-2013

The above accident reports shows that the barrier collision accident rate is increased more than double times and these accidents mostly happened at night time.

\subsection{Proposing of New Technique to Reduce barrier}

\section{Collision Accident}

After analyzing the various barrier collision accidents and examining the location of accidents happened the below techniques are proposed, which may reduce the Barrier Collision Accident.

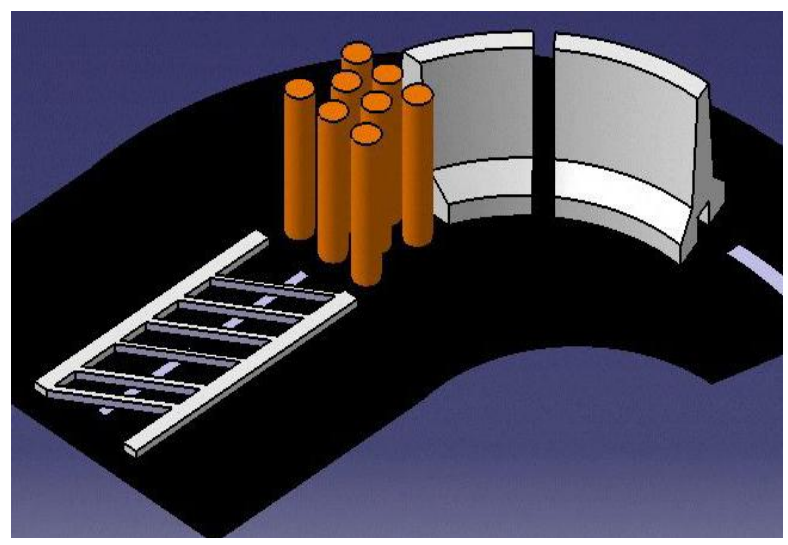

Fig -3.1: Arrangement of Flexible Barriers

- Fixing the FLEXIBLE BARRIER in Zigzag manner in front of the Jersey Barrier (Fig- 3.1)

- Constructing the small Speed Breakers (Rumble Strips) over the Restricted Path (White Marking) made in front of the Flexible Barrier (Fig- 3.1)

The Rumble strip arrangement is made to reduce the speed of the vehicle and also to alert driver about the hazard. The Zigzag arrangement of the flexible barrier will be suitable for both 2-wheeler and 4-wheeler accidents. When 2wheeler hits the barrier it will get in between the gap provided in the barrier arrangement. And when 4-wheeler hits the barrier then the barrier will get flexed and accident effect will be reduced.

\subsection{Analyzing the Property of Material to be used for New Barrier}

Flexible PVC is a Flexible Plastic Material. It is manufactured from Anti-Ageing customized plastic compound with PVC as a base polymer and Exhibiting required properties like

- High Elasticity Strength,

- High Tensile Strength,

- Can bear shocks of heavy turbines,

- Excellent weather resistant,

- Unaffected by acids, alkalis, metals salts and other chemicals,

- Lower water absorption,

- Immune to Corrosion,

- Withstand high Hydrostatic pressure, Earth quakes, Floods etc...

Table -3.1: Physical and Mechanical Properties of Flexible PVC

\begin{tabular}{|c|c|c|}
\hline PROPERTY & $\begin{array}{l}\text { TEST } \\
* \text { ASTM }\end{array}$ & VALUE \\
\hline Water absorption & *D570 & 0.02 \\
\hline Tear Resistance & *D624 & 225 lb./in. \\
\hline Ultimate Elongation & *D638 & $360 \%$ \\
\hline Tensile Strength & *D638 & $\begin{array}{l}2000 \text { psi min.(1379 } \\
\left.\mathrm{N} / \mathrm{cm}^{2}\right)\end{array}$ \\
\hline $\begin{array}{l}\text { Low Temperature } \\
\text { Brittleness }\end{array}$ & *D746 & Passed @-35 ${ }^{\circ} \mathrm{F} /-37^{\circ} \mathrm{C}$ \\
\hline Stiffness in Flexure & $*$ D747 & 700 psi min. $\left(483 \mathrm{~N} / \mathrm{cm}^{2}\right)$ \\
\hline Specific Gravity & *D792 & 1.40 \\
\hline $\begin{array}{l}\text { Hardness Shore } \\
\text { A15 }\end{array}$ & $* \mathrm{D} 2240$ & $79 \pm 3$ \\
\hline $\begin{array}{l}\text { Accelerated } \\
\text { extraction } \\
\text { - } \quad \text { Tensile strength } \\
\text { - } \quad \text { Elongation } \\
\text { Effect of Alkali } \\
\text { - Weight change } \\
\text { - } \quad \text { Hardness } \\
\quad \text { Change }\end{array}$ & $\begin{array}{l}\text { CRD-C } \\
572\end{array}$ & $\begin{array}{l}1850 \mathrm{psi}\left(1276 \mathrm{~N} / \mathrm{cm}^{2}\right) \\
360 \% \\
+0.10 \% \\
+1 \text { point }\end{array}$ \\
\hline
\end{tabular}

The physical and mechanical properties of the Flexible PVC shows (see Table 3.1) that it is good in Tensile strength, Ultimate elongation, Flexural strength and also passed in Low temperature test etc.. So, it shows that this material will be suitable for the new flexible barrier.

\subsection{Design and Analysis of Flexible Barrier}

The size and shape of the Flexible barrier is designed after analyzing the vehicle properties and previous type of barriers and its performances. The Flexible barrier is provided with nail hole at bottom for fixing the flexible barrier to the road. And also it can be fixed below the ground using concrete. The new flexible barrier is provided with base diameter $0.18 \mathrm{~m}$, height $0.85 \mathrm{~m}$ and weight is $12.5 \mathrm{~kg}$. And the post bottom diameter is $0.13 \mathrm{~m}$ and top diameter is $0.1 \mathrm{~m}$ (see Fig - 3.2). 


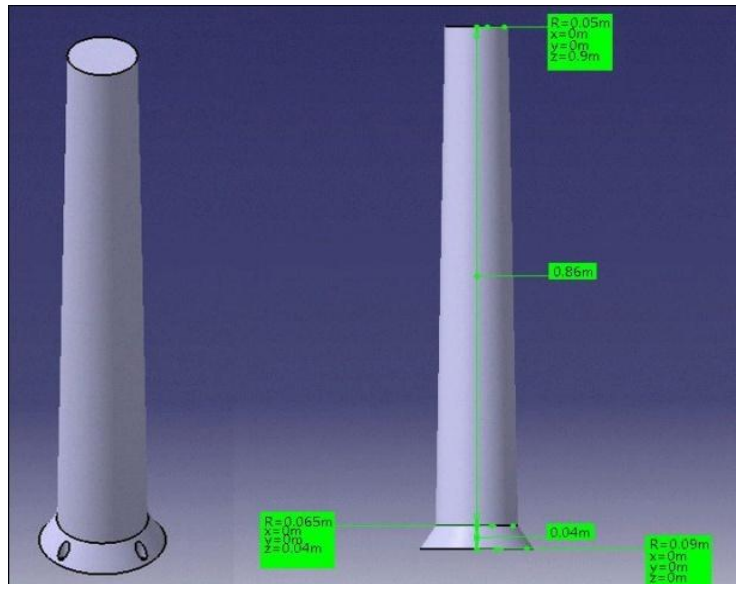

Fig -3.2: Design details of Flexible Barrier

After the design the created model is analyzed using ANSYS analysis software. The model is tested with the specifications mentioned in the "Guidelines and Specifications for Crash Barriers, Pedestrians Railings and Dividers" released by Delhi Development Authority, Unified Traffic and Transportation Infrastructure Planning \& Engineering Centre (UTTIPEC).

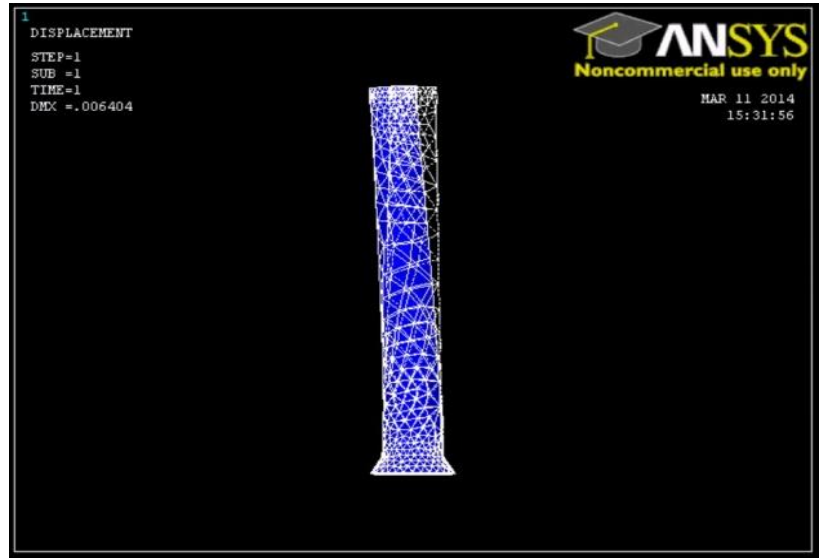

Fig -3.3: Displacement of Flexible Barrier when applying load

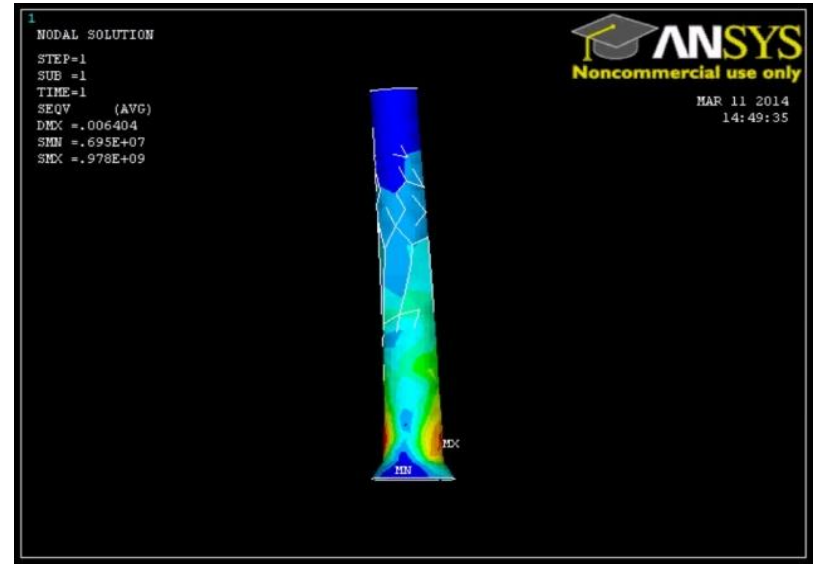

Fig -3.4: Nodal solution Flexible Barrier when applying load in ANSYS
The analysis report show (see Fig- 3.3 and Fig- 3.4) that the designed model is withstands the $30 \mathrm{KN}$ vehicle load at 65 $\mathrm{km} / \mathrm{hr}$ at 20 degree angle of impact and more stress is created at the bottom of the barrier.

\subsection{Cost Analysis}

The cost comparison analysis of Flexible PVC Barrier and RCC Barrier is given below.

\subsubsection{Cost for RCC Barrier}

Current market price for RCC Median divider block (per piece) $=$ Rs. 3900.00

\subsubsection{Calculation for Cost of Flexible PVC Barrier}

(i) Volume of Frustum of Cone $(\mathrm{V})=[\pi \mathrm{h} / 12]^{*}\left[\mathrm{~d}^{2}+\mathrm{Dd}+\mathrm{D}^{2}\right]$ ( $h=$ height of cone, $\mathrm{D}=$ bottom diameter, $\mathrm{d}=\mathrm{top}$ diameter)

Volume of top cone (v1)

$$
\begin{aligned}
(\mathrm{v} 1) & =[\pi 0.86 / 12] *\left[0.1^{2}+(0.1 * 0.13)+0.13^{2}\right] \\
& =0.225 * 0.0399 \\
(\mathrm{v} 1) & =0.00898 \mathrm{~m}^{3} .
\end{aligned}
$$

Volume of bottom cone (v2)

$$
\begin{aligned}
(\mathrm{v} 2) & =[\pi 0.04 / 12] *\left[0.13^{2}+(0.13 * 0.18)+0.18^{2}\right] \\
& =0.0105 * 0.0727 \\
(\mathrm{v} 2) & =0.000763 \mathrm{~m}^{3}
\end{aligned}
$$

Total Volume $(\mathrm{V})=\mathrm{v} 1+\mathrm{v} 2$

$$
=0.00898+0.0007634
$$

Total Volume $(\mathrm{V})=\mathbf{0 . 0 0 9 7 4 3} \mathrm{m}^{3}$

(ii) Density $\quad=1300 \mathrm{~kg} / \mathrm{m}^{3}$

(iii) Weight per Piece $(\mathbf{W})=$ volume $*$ density

Weight per Piece $(\mathrm{W}) \quad=12.7 \mathrm{~kg}$

Current market price for Flexible PVC material (including Manufacturing cost for production of 1 lakh piece) (per kg) = Rs. 150 (approx.)

(iv) Cost for 1 piece $=\mathrm{W} *($ cost of $1 \mathrm{~kg})$

$$
=12.7 * 150
$$

Cost for 1 piece $=$ Rs. 1905.00

When compared to the cost of RCC Barrier the Flexible PVC Barrier cost is less. And we can purchase 2 Flexible PVC barriers at cost of buying a single RCC Barrier. And also Flexible PVC barrier has the advantage of reducing effect of during barrier collision accident.

\section{CONCLUSIONS}

The increase in accident scenario needs appropriate solutions to reduce the effect of accidents. In view of the above, the existing barrier performances are analyzed and to overcome the problems in existing barrier, a new Flexible Barrier system is introduced. The properties and analysis report of the Flexible PVC Barrier ensure that installation of this barrier in the accident prone zones will reduce the barrier collision accidents and its effects. 
Rumble strip arrangement is made to reduce the speed of the vehicle and also to alert driver about the hazard. The Zigzag arrangement of the flexible barrier will be suitable for both 2-wheeler and 4-wheeler accidents. When 2-wheeler hits the barrier it will get in between the gap provided in the barrier arrangement. And when 4-wheeler hits the barrier then the barrier will get flexed and accident effect will be reduced.

When compared to the cost of RCC Barrier the Flexible PVC Barrier cost is less. And also Flexible PVC barrier has the advantage of reducing effect of during barrier collision accident.

\section{REFERENCES}

[1] Jason S. Stine, Bridget C. Hamblin, Sean N. Brennan, Eric T. Donnell, "Analyzing the influence of median cross-section design on highway safety using vehicle dynamics simulations" Accident Analysis and Prevention 42 (2010) Page: 1769-1777.

[2] Richard Tay, "Effect of different median barriers on traffic speed" Canadian Journal of Transportation, Vol 1, No 1 (2007) Page: 1-7.

[3] Peter Wright, "Barriers", grandprix.com (July21, 2001).

[4] Salvatore Cafiso, Giacomo Di Silvestro, Giovanni Di Guardo, "Application of Highway Safety Manual to Italian divided multilane highways" Procedia-Social and Behavioral Sciences 53 (2012) Page: 911 - 920.

[5] Robert B. Noland, Lyoong Oh, "The effect of infrastructure and demographic change on traffic related fatalities and crashes: a case study of illinois country - level data" Accident Analysis and Prevention 36 (2004) Page: 525-532.

[6] Marisol Castro, Rajesh Paleti, Chandra R. Bhat, "A spatial generalized ordered response model to examine highway crash injury severity" Accident Analysis and Prevention 52 (2013) Page: 188- 203.

[7] Camille A. Issa, George Salem, "Utilization of recycled crumb rubber as fine aggregates in concrete mix design" Construction and Building Materials 42 (2013) Page: 48-52.

[8] "Guidelines and Specifications for Crash Barriers, Pedestrians Railings and Dividers" released by Delhi Development Authority, Unified Traffic and Transportation Infrastructure Planning \& Engineering Centre (UTTIPEC).

[9] Mr. Ho Seng Tim, "UNESCAP Expert Group Meeting on Improving Road Safety" Paper on Road Safety, Land Transport Authority, Singapore (May2006).

[10] FIR Index 2011-2013 (Tiruchengode Rural Police Station)

[11] FIR Index 2013 (July - December) Ammapet Police Station, Traffic Investigation Wing (North Range), Salem

[12] Road accidents in India 2012, Book Released by Government of India, Ministry of Road Transport \& Highways (MORTH), Transport research wing, New Delhi.
[14] Malaimalar (Tamil daily evening Newspaper)

[15] PVC Water Stop, http://www.pvcwaterstop.in/ , (2014).

[16] International Water stops for concrete, http://www.Greenstreak.com/ , (2014).

\section{BIOGRAPHIES}

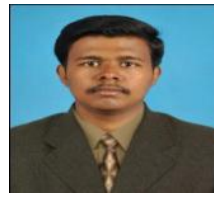

Mr.G.Udayakumar, B.E., (Civil) and currently pursuing M.E., (Industrial Safety Engineering) in K.S.Rangasamy College of Technology, Tamilnadu, India. Email: uday.g17@gmail.com

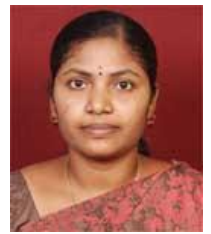

Ms.S.Chandralekha, M.E.,(Ph.D.,) and currently working as a Assistant Professor (Dept. of Mechatronics Engineering) in K.S.Rangasamy College of Technology, Tamilnadu, India. Email: chandralekha@ksrct.ac.in

[13] The Hindu (English daily Newspaper) 